\title{
Reflexiones sobre el espacio migrante en la narrati- va de Amara Lakhous ${ }^{1}$
}

\author{
Reflections on the Migrant Space in the Narratives \\ of Amara Lakhous
}

\author{
BEgoña PoZo-SÁNCHEZ \\ (Universitat de València) \\ Begona.Pozo@uv.es
}

\begin{abstract}
Resumen: La literatura migrante italiana actual transita ciertos espacios heterotópicos que, siguiendo la propuesta teórica de Michel Foucault, inciden especialmente en la creación y el análisis de esos no-lugares que, bien desde la utopía o desde la heterotopía, analizan la situación social a través de la literatura. «Italia» se convierte así en un territorio al que llegar, conocer, habitar pero, sobre todo, desde el que construir realidades otras. Esta perspectiva de la literatura actual no aparece solo en obras escritas «en» italiano y «desde» Italia -como, por ejemplo, Scontro di civiltà per un ascensore a Piazza Vittorio, publicada por Amara Lakhous en 2006; o como las propuesta poéticas transculturales de la Compagnia delle Poete- sino también «en» otras lenguas y «desde» otras miradas - quizá uno de los ejemplos relativamente recientes sea el texto Vergogna tra le due sponde del escritor egipcio Ezzat el Kamhawi, a medio camino entre la novela y el ensayo. Nuestro artículo se centra en el estudio de la construcción de la identidad migrante a través del análisis de la poética del espacio propuesta por Amara Lakhous, evidenciando cómo desde distintas realidades transculturales se aborda y (re)crea actualmente el concepto de «Italia» a partir del discurso literario, a modo incluso de polémico «contra-espacio».
\end{abstract}

Palabras clave: Literatura migrante italiana, poética del espacio, Amara Lakous.

\begin{abstract}
Current Italian migrant literature goes along certain heterotopic spaces which, following Michel Foucault's theoretical proposal, influence especially on the creation and analysis of those no-places that, either from utopia or heterotopia, scrutinise the social situation through literature. Thus,
\end{abstract}

\footnotetext{
${ }^{1}$ Esta investigación se realiza dentro del marco del proyecto de excelencia I+D+I de «Cultura y Nuevos Movimientos Sociales: prácticas, discursos y representaciones» (FFI2014-55207-P), concedido por el Ministerio de Economía y Competitividad.
} 
«Italy» becomes a place to get, discover, dwell in but, especially, from which to construe other realities. This perspective of current literature does not only feature in works written «in» Italian and «from» Italy - as, for instance, Scontro di civiltà per un ascensore a Piazza Vittorio, published by Amara Lakhous in 2006; or as transcultural poetic proposal by the Compagnia delle Poete- but also «in» other languages and «from» other stances - one of the most recent texts is perhaps Vergogna tra le due sponde by the Egyptian writer Ezzat el Kamhawi, midway between novel and essay. This articles focuses on studying the construction of migrant identity by analysing the poetics of space proposed by Amara Lakhous, showing how the idea of «Italy» is currently dealt with and recreated in literary discourse from distinct transcultural realities, even in a polemical «counter-space» way.

Key words: Italian migrant literature, poetics of space, Amara Lakous.

El transitar por lugares teóricos abiertos y conectados -como los estudios culturales, la psicología transcultural o la literatura de la migración-; el centrarse en cuestiones que no eluden el conflicto - ni humano ni, en consecuencia, literario- como la memoria, el exilio, la otredad o la exofonía; o el analizar propuestas literarias que, solo en tiempo reciente, empiezan a gozar de cierto reconocimiento por parte del canon literario y de la institución denominada «Literatura» pero que hasta un tiempo bastante reciente han sido consideradas como marginales y de poco peso en la literatura italiana canónica, nos han llevado a ocupar lo que podríamos considerar una «posición heterotópica». Siguiendo la clasificación propuesta por Foucault en sus conferencias radiofónicas de 1966 -recogidas por escrito en 1984-, el espacio se subdivide en dos grandes tipos: las utopías y las heteropías. Las primeras son «los emplazamientos sin lugar real» ${ }^{2}$, las segundas «los emplazamientos otros que, sin embargo, reflejan por oposición a las utopías» ${ }^{3}$. La articulación del pensamiento foucaultiano es sumamente compleja y no se trata de centrarnos aquí solo en estas cuestiones - dada la limitación de nuestra intervención-, sino de observar cómo su pensamiento filosófico - a su vez ligado a la fenomenología de la imaginación que tanto admiró, especialmente la de Bachelard- encaja con una de las obras de narrativa migrante más significativa de los últimos años -Scontro di civiltà per un ascesore a Piazza Vittorio (2006)-; todo ello con el objetivo final de ver cómo desde la literatura actual en lengua italiana producida por escritores alófonos se está dibujando un mapa distinto de la realidad socio-cultural italiana, es decir, se están creando unos «contraespacios» que, regresando al pensamiento de Foucault, nos permite identificar ese lugar como un espacio

2 Conferencia de Michel Foucault, «Des espaces autres / De los espacios otros», dictada en el Cercle des études architecturals el 14 de marzo de 1967 y publicada en Architecture, Mouvement, Continuité (1984). Se cita por la traducción de Pablo Blitstein y Tadeo Lima.

3 Idem. 
absolutamente diferente de otros, destinado entonces a «borrarlos, compensarlos, neutralizarlos o purificarlos» ${ }^{4}$.

Tras estas indicaciones generales del tema que proponemos, nos gustaría acercarnos de forma algo más detallada a la cuestión central que abordaremos a lo largo de estas páginas: cómo la literatura migrante italiana actual transita ciertos espacios heterotópicos, incidiendo en la creación de esos no-lugares que, bien desde la utopía o desde la heterotopía, analizan la situación social a través de la literatura. «Italia» se convierte así en un territorio al que llegar, conocer, habitar pero, sobre todo, desde el que construir realidades distintas. Esta perspectiva de la literatura actual no aparece solo en obras escritas «en» italiano y «desde dentro» Italia -como, por ejemplo, la citada Scontro di civiltà per un ascensore a Piazza Vittorio o como las propuestas poéticas transculturales de la Compagnia delle Poete que ya hemos analizado teóricamente en diferentes sedes-; sino también «en» otras lenguas y «desde fuera» de Italia, ampliando el panorama a otras miradas que enriquecen y complementan la imagen de lo que, por tradición histórica y cultural, hemos considerado que es «Italia». En este sentido quizá uno de los ejemplos más interesantes sea el texto Vergogna tra le due sponde. La schiavitù contemporánea nel Mediterraneo del escritor egipcio Ezzat el Kamhawi, a medio camino entre la novela y el ensayo, que vio la luz en 2014 en la colección Trasculturazione -dirigida por el comparatista italiano Armando Gnisci- y que aporta una mirada necesaria para entender qué está pasando a día de hoy en el Mediterráneo y, en concreto, en las costas del sur de Italia.

Como apunta Stefano Zangrando (2010), a estas alturas la presencia de la literatura migrante en Italia viene refrendada por una producción notable y es ya bastante sólida. En nuestro caso hemos decidido centrarnos en la escritura de Amara Lakhous (Argel, 1970), trazando conexiones transversales con la de Ezzat el Kamhawi (Mit Suhayl, Sharqiya, 1961). A pesar de los puentes que las unen, será sobre la novela del escritor, periodista y traductor argelino donde nos detendremos con mayor atención debido a que es esta la que goza de un marcado carácter literario. Por lo que respecta a la obra del escritor y periodista egipcio, considerando que se acerca más al formato del ensayo, hemos querido mantenerla en un segundo plano desde donde puede apuntar cuestiones decisivas relativas, sobre todo, al actual marco socio-cultural de los movimientos migratorios. Además, dado que las cuestiones que vamos a ir mencionando no son exclusivas de sus escrituras, permiten su conexión inmediata con el resto de corpus donde podemos identificar otros textos próximos por cuestiones de estilo, temática, género, etc. Para acercarnos a estas propuestas narrativas hemos establecido tres ejes que nos van a permitir reflexionar sobre distintos aspectos a tratar: la literatura como choque cultural, donde abordaremos especialmente las cuestiones relacionadas con la lengua y el espacio; la literatura como fuente de conocimiento, donde nos aproximaremos al valor la experiencia indirecta y de la traducción -no solo lingüística, sino también cultural (Grossman, 2010)-; y la literatura como espacio de libertad, donde ahondaremos en el valor artístico

\footnotetext{
${ }^{4}$ Idem.
} 
-intrínseco y necesario- de los textos. Todo ello para mostrar hasta qué punto ambas propuestas son convergentes en cuanto escrituras híbridas o transgenéricas y, sobre todo, qué pueden aportar a la literatura italiana actual.

Comenzar hablando de la literatura como choque cultural nos permite un anclaje directo con la novela de Lakhous a partir del título mismo: Scontri de civiltà per un ascensore a piazza Vittorio. El libro fue publicado por primera vez en el año 2006 por la editorial romana e/o, momento en que se alzó con el Premio Flaiano de narrativa; posteriormente le fue concedido el galardón Racalamare-Leonardo Sciascia de 2006 y en 2008, por la misma obra. También recibió por esa novela el premio literario más importante de Argelia: el de los libreros argelinos. El éxito de la publicación fue casi inmediato y, además de contar hasta el momento con diversas reediciones (2011 y 2014), también ha sido objeto de una adaptación cinematográfica a cargo de Isotta Toso (2010).

Esta conexión innegable apunta también a la importancia del elemento paratextual. El título extenso en el que se enmarca la novela desde su inicio alude a ciertos elementos que van a ser determinantes en el desarrollo de la trama, de los espacios, de los personajes y que, en consecuencia, van a condicionar la propuesta narratológica del autor mediante el recurso a ciertas estrategias discursivas. La presencia de términos como scontro, civiltà, ascensore o piazza Vittorio nos dirigen, como lectores, a unos territorios donde sugerencia y concreción van de la mano, insinuando así otro de los recursos determinantes para la construcción novelística de Lakhous: una ambigüedad narrativa totalmente necesaria para el desarrollo de un giallo -si queremos, sui generis, dadas sus conexiones con la forma de la escritura diarística- que tendrá como epicentro un ascensor de una comunidad en la multiétnica Piazza Vittorio de Roma -cercano a ese «no lugar» del que hablábamos anteriormente-. La imprecisión apuntada desde el título -nótese, por ejemplo, que no aparece ningún artículo determinado- va a marcar el camino constante de lo que podríamos llamar una «deslocalización voluntaria» por parte del narrador y que, contrariamente a lo que pudiese parecer en un primer momento, va a redundar en la localización concreta y en la rápida identificación de los personajes que pueblan estas páginas. Precisamente la búsqueda del equilibrio entre las máscaras de cada uno de los individuos y la colectividad a la que pertenecen, la civiltà, se convierte en garantía de superación del conflicto cívico, del scontro, que parece casi inevitable cuando nos acercamos a un argumento literario donde se aborda la convivencia cotidiana de grupos culturales diversos.

El desencuentro ciudadano ha sido objeto de estudio por parte de diferentes disciplinas -como la antropología y la psicología social o, de creación más reciente, la denominada psicología transcultural- y, además, es precisamente una de las características recurrentes en las obras que abordan el tema de la migración desde una perspectiva literaria. Como apunta Edelia Villarroya en el número 81 de la revista Mètode $e^{5}$, un monográfico dedicado a Itineràncies (dis-

${ }^{5}$ Revista de difusión de la investigación publicada por el Vicerrectorado de Investigación de la Universitat de València y dirigida por el profesor y escritor Martí Domínguez. Se puede consultar en papel o en formato electrónico (http://metode.cat/). 
persió, migració, diàspora), en todo proceso de aculturación se producen tres fases: el contacto, el conflicto y la adaptación. En palabras de Villarroya (2014:52) el primero «és necessari i pot ser físic o simbòlic»; el segundo «és inevitable» y el tercero «s'entén com la resolució del conflicte». Este proceso tendrá unas consecuencias tanto políticas como socio-culturales en ambas sociedades -sea la de origen, sea la de llegada-, si bien vamos a mencionar solo aquellas que afectan al marco sociocultural puesto que es el que, de forma evidente, se aborda a lo largo de las páginas de la novela con una ironía fresca no exenta de nostalgia.

Como describe Villarroya (2014:53) en su análisis sobre el impacto social de la movilidad humana, los efectos socioculturales en ambas sociedades son positivos y negativos. En la sociedad de origen los positivos implican la «arribada de noves «formes de vida» que qüestionen aspectes de les anteriors» y la «major inversió en l'educació dels joves»; en la de llegada suponen la «trobada de diferents cultures» y el «augment de la mobilitat social». Por lo que respecta a los efectos negativos, en el caso de la sociedad de origen nos encontramos con la «desintegració familiar», la «promoció de l'emigració com a estratègia de desenvolupament» y la percepción de «les comunitats migrants com "vaques lleteres"»; mientras que en la sociedad de llegada hallamos «fenòmens d'intolerància i xenofòbia», la «creació de guetos» i la «criminalitat organitzada que es nodreix de la inmigració irregular». Todas las cuestiones que menciona Villarroya $-\mathrm{y}$ que responden a lo que Ovejero ha definido en su vertiente literaria como «psicología intuitiva» (2012:8)- podemos rastrearlas a lo largo del cuerpo de la novela tratadas desde la perspectiva que Christiana de Caldas Brito ha identificado como «scambio d'occhi», es decir, mediante el recurso a una perspectiva no eurocéntrica donde la sociedad italiana es vista y descrita en el texto con «otros» ojos, provocando así un vuelco en la mirada.

Para generar esa mirada otra desde el texto, el narrador interviene en diversos niveles que, si bien los separaremos ahora por razones metodológicas, en el cuerpo de la novela aparece imbricados con gran maestría, convirtiendo el texto literario en un artefacto preciso que conecta su propuesta a la tradición de lo que se ha venido identificando -no sin ciertos problemas genéricos y de denominación (Meneghelli, 2012) - como literatura migrante, es decir, por una temática vinculada a la experiencia migratoria de los personajes. El caso planteado por Amara Lakhous va más allá porque el peso de la experiencia vital de los inmigrantes no se convierte en el eje temático central de la novela y su situación, si bien es determinante para la realización del proyecto vital de los protagonistas, es abordada de forma tangencial -que no superficial- con la finalidad de no convertirla en el objeto prioritario. Desplazar el foco de atención hacia el asesinato de Lorenzo Manfredini, un personaje algo oscuro conocido como Il gladiatore, permite al narrador organizar la arquitectura textual de forma original. El cuerpo del asesinado aparece en un ascensor y todos los indicios apuntan a Amedeo, protagonista que desaparece justo después de esta muerte violenta. Su ausencia inesperada es la que hace recaer sobre él las sospechas de la policía pero, en ningún caso, las de sus vecinos y conocidos. Cada uno contará «su verdad» sobre Amedeo quien, por otra parte, desarrolla la doble figura de personaje y narrador puesto que en ciertas secciones habla en primera persona 
como responsable de la escritura de un diario que aparece de forma paralela a la narración de la historia y, en otras, se convierte en el argumento de las intervenciones del resto de personajes. Este juego de focalizaciones internas y externas confiere una complejidad al texto que, además, se suma a la corriente de novela negra donde misterio, ambigüedad y sospecha hacen que el lector reciba la información de forma progresiva, intentando mantener en suspensión la acción. A ello hay que añadir la transición permanente entre diversos moldes genéricos ya que la novela se construye en función del desarrollo en paralelo de una historia -donde cada capítulo es narrado desde el punto de vista del personaje que le da título, por ejemplo, «La verità di Parviz Mansoor Samadi»-y de los capítulos de un diario escritos todos por Amedeo -y titulados «Primo ululato», «Secondo ululato», etc.- con la finalidad de dar al lector una mirada distinta y complementaria a la historia que se acaba de contar. Con este rompecabezas el autor propone un texto que requiere una lectura activa porque ninguna de las verdades de cada capítulo lo es de forma absoluta. Solo podremos acercarnos a una verdad compleja cuando hayamos accedido a la información que se nos da desde cada sección y hagamos una recomposición de lo sucedido. Por supuesto, la dosificación de la información jugará un papel determinante para mantener el suspense y provocar la sorpresa final -que, por supuesto, no vamos a desvelar aquí y que dejamos en el aire para despertar la curiosidad por la lectura de la novela-, permitiéndonos entonces tener una visión total de lo sucedido.

En este juego los espacios que ya hemos ido mencionado ostentan un papel decisivo y se convierten en lo que Bajtin (1986) definió como «cronotopo» de la novela, es decir, esa unión de relaciones temporales y espaciales que producen conexiones esenciales, creando núcleos de significados que sostienen y hacen avanzar el relato. En este sentido, la novela de Lakhous se articula en diferentes cronotopos, justamente esos espacios indeterminados que mencionados ya en el título -ascensore y piazza- van a convertirse en epicentros de la novela, adquiriendo una gran relevancia respecto al resto de elementos compositivos. Precisamente toda la acción se ve determinada por la aparición de un muerto - de quien se aporta poquísima información: hombre rudo, maleducado y racista- en un ascensor, siendo este descubrimiento el detonante de la acción puesto que el hilo argumental que se empieza a trazar es el del asesinato de «un italiano» a manos de «un inmigrante». Los comentarios con marcados tintes racistas protagonizados por Benedetta, la portera napolitana, aparecen desde las páginas iniciales y van a ser constantes a lo largo de toda la novela porque ella, como el ascensor, es el punto de conexión entre los demás protagonistas -como si estuviésemos contemplando unas «vidas cruzadas» al estilo del cineasta Robert Altman-. El capítulo donde se narra «La verità di Bendetta Esposito» está cargado de grandes dosis de ironía, recurso que el narrador domina a la perfección para crear hilaridad en el lector $\mathrm{y}$, al mismo tiempo, denunciar la gran cantidad de tópicos negativos que se acumulan en torno a la población inmigrante. En el caso de Benedetta, quien ejerce el poder sobre el uso del ascensor desde su atalaya de «cotilla oficial», la confusión continua entre nacionalidades, nombres, costumbres y vidas tortuosas - cuando no marginales- de la mayoría de los habitantes cercanos a su palazzo, provoca un estupor inicialmente risueño que, sin embargo, se irá transformando progresivamente en agresivi- 
dad verbal. Numerosos son los ejemplos de su capítulo, aunque traemos a colación uno que puede ejemplificar bien las características apuntadas del personaje:

Io sono sicura che l'assassino di Lorenzo Manfredini è uno degli immigrati. Il governo debe reagire ampressa ampressa. Un altro poco ci cacceranno dal nostro paese. Basta che fai un giro di pomeriggio nei giardini di Piazza Vittorio per vedere che la stragrande maggioranza della gente sono forestieri: chi viene dal Marocco, chi dalla Romania, dalla Cina, dall'India, dalla Polonia, dal Senegal, dall'Albania. Vivere con loro è impossibile. Tengono religioni, abitudini e tradizioni diverse dalle nostre. Nei loro paesi vivono all'aperto o dentro le tende, mangiano con le mani, si spostano con i ciucci e cammelli e trattano le donne come schiave. Io non sono razzista, ma questa è la verità (pp. 36-37).

La última frase es probablemente una de las justificaciones más habituales después de un discurso de carácter xenófobo, sea cual sea la procedencia del hablante. De este modo vemos cómo la distancia justa y el conocimiento profundo de una cultura se transmiten en clave humorística a través de uno de los personajes más grotescos de la novela, junto con el de Elisabetta Fabiani, otra italiana doc que achaca la desaparición de su perro a las mafias chinas que consumen este tipo de carne en sus restaurantes.

Sin embargo, no se trata exclusivamente de manifestar ciertas ofensas a través de los comentarios racistas de algunos personajes. A lo largo de la historia asistimos a diversos incidentes provocados por el ambiente xenófobo de la sociedad en la que viven los protagonistas y que lleva a alguno de ellos a reacciones desproporcionadas a causa de la desesperación y de la incomprensión en la que hallan inmersos. Así una de las imágenes más impactantes de la novela aparece ya en el primer capítulo donde Parviz, el cocinero iraní que ansía el asilo político, se cose literalmente la boca para oponerse con su silencio obligado a una injusta acusación policial. Esta visión espeluznante provoca una hondísima tristeza en Amedeo quien, a partir de ese primer capítulo seguido del primer grito, comenzará a tejer el resto de relaciones interpersonales que darán forma al cuerpo de la novela. Esta desesperación, si bien narrada en clave ensayística, es también la que denuncia Ezzat el Kamhawi en su ensayo Vergogna tra le due sponde donde, centrándose en el éxodo de jóvenes egipcios hacia el sur de Italia -antes hacia Roma, ahora hacia Milán- denuncia cómo esto se produce por la connivencia jurídica y económica entre los estados italiano y egipcio, las redes mafiosas y las propias familias que empujan a sus hijos hacia el fatal viaje que, en la mayoría de los casos, acaba en desaparición y muerte. El análisis sociológico sobre la sociedad actual realizado por este conocido periodista y novelista egipcio nos pone sobre la pista de la situación que se está repitiendo a lo largo de todas las costas del Mediterráneo, sin excepción.

Esta situación, precisamente, es la misma que atravesó el personaje de mayor peso de la novela, Amedeo, a quien todos consideran un italiano doc por su gran dominio del italiano, por sus exquisitos modales, por su cordialidad y amabilidad a la hora de ayudar a inmigrantes ante la burocracia estatal -permi- 
sos de residencia, altercados con la policía, ayudas en servicios sociales, etc.pero, sobre todo, porque cuando le preguntan de dónde viene siempre responde que «dal sud», «dal sud sud»-recalca con esa estructura reiterativa clásica de la lengua italiana. Y aquí nos tendríamos que adentrar en una cuestión casi de filosofía espacial: ¿dónde está el sur para los italianos? Dada la relatividad de la frontera psicológica entre norte y sur, como es bien sabido para cualquiera que se haya acercado a la cultura italiana, no nos detendremos en esta cuestión. Solo apuntar que uno de los personajes que pueblan la novela, Antonio Marini, profesor universitario de historia contemporánea nacido en Milán pero que ejerce desde hace años en Roma -si bien fue para un curso y está a punto de jubilarse-, ante la impuntualidad y el retraso descarado del que alardean los conductores de autobús en Roma se pregunta:

E la madonna! Dove l'è che sem? A Mogadiscio o a Addis Abeba? Sèm a Roma o a Bombay? Nel mondo sviluppato o nel terzo mondo? Fra poco ci cacceranno dal club dei richhi. Queste cose al nord non succedono. Io sono di Milano e non sono abituato a questo caos (p. 73).

Pero volvamos a nuestro protagonista del sur, Amedeo, que, en realidad, no es Amedeo, sino Ahmed. La cuestión nominativa será también otro elemento decisivo que solo conoceremos en los capítulos finales cuando su mujer, Stefania Massaro, inicie su hisoria preguntándose «Chi è il vero Amedeo?» (p. 101) o cuando su compatriota, Abdallah Ben Kadour, inicie su narración con la cuestión «Perché si è fatto chiamare Amedeo?» (p. 112). El cambio fortuito de nombre -justificado por la tendencia habitual de los italianos a no pronunciar las «h» aspiradas, como se comenta en un pasaje de la novela- produce el principal equívoco sobre el que se construye la novela: la verdadera identidad, migrante o no, del protagonista. A esta hay que sumar otros elementos que la acompañan de forma inevitable: el silencio sobre su pasado y sobre su procedencia, pero también la creación de una nueva identidad -con todas las posibilidades que ello conlleva. La ocultación voluntaria del origen y de la memoria, en el caso de Ahmed/Amedeo, se convierten en un mecanismo de supervivencia para poder afrontar su futuro con algo más de esperanza; para poder medirse cada día con el dolor de ciertas pérdidas que, en ocasiones, lo asedian desde el sufrimiento tamizado de los sueños. Así explica la aparición de ciertos gritos nocturnos -«Bàgia! Bàgia!» (p. 105)- que sorpenden a Stefania:

Il maledetto incubo mi perseguita. Stefania mi ha detto questa mattina che ho gridato durante il sonno e che ho ripetuto molte volte il nome Bàgia. Non ho voluto rivelarle i dettagli. È inutile farla partecipare al gioco degli incubi. La mia memoria è ferita e sanguina, devo curare le ferite del passato in solitudine. Peccato, Bàgia si fa viva solo negli incubi avvolta in un lenzuolo machiato di sangue. Oh, mia ferita aperta che non guarirai mai! Non ho consolazione al di fuoir dell'ululato (p. 109).

Por lo tanto, en su caso vemos que no existe consolación más allá del «ululato», es decir, más allá de ese grito escrito que desde su diario va recomponiendo, a partir de la soledad de la escritura, el texto dolorido de su experiencia. 
Como puede comprobarse tras estas reflexiones, acercarse a la novela de Lakhous es como empezar a comerse una cesta llena de cerezas: unas se enganchan con otras, es difícil separarlas y, sobre todo, resulta complicado sustraerse al deseo de seguir comiendo. Sin embargo, deberíamos pensar en dejar algunas cerezas para otros futuros lectores y lectoras. Con los ejemplos que hemos aportado de la novela consideramos que se ha podido detectar el ritmo ágil y el nervio de la narración, así como el tono vibrante de sus personajes. En este sentido la prosa de la novela presenta una gran calidad y hace que su lectura sea amena, además de compleja si no perdemos de vista las cuestiones estructurales que ya hemos comentado. De ahí que a esta primera novela en italiano de Amara Lakhous haya sido solo el inicio de una estimulante carrera que ya cuenta con otros títulos como: Divorzio all'islamica a viale Marconi (2010); Un pirata piccolo piccolo (2011); Contesa per un maialino italianissimo a San Salvario (2013) y La zingarata della verginella di Via Ormea (2014).

Si a las cuestiones estilísticas y formales que hemos comentado, añadimos la capacidad del narrador para transmitir al lector el universo difícil al que se enfrentan tanto los inmigrantes como las sociedades que los acogen sin abandonar un tono marcado por el uso del humor inteligente, tendremos que reconocer el interés y la calidad de la propuesta literaria de Amara Lakhous. Con su obra se refuerza el valor de la literatura como fuente de conocimiento del otro al transmitir, mediante la experiencia indirecta, otras realidades que, desde la ficción, permiten «ampliar nuestra capacidad de explorar a través de la literatura las ideas y los sentimientos de gente de otra sociedad» (Grossman, 2010: 26). Con sus narraciones la literatura se convierte pues en espacio de libertad y en fuente de conocimiento, como decíamos al inicio de nuestro artículo. Esperamos, a pesar de las limitaciones, haber abierto esa ventana indispensable a la que asomarse de vez en cuando para poder contemplar la vastedad del horizonte, para sabernos parte de un paisaje, para superar los muros que atenazan con visiones únicas y reducidas, para saltar sin miedo a las páginas que nos recuerdan la riqueza y la pluralidad, para no dejarnos apresar por pequeños espacios aislados. A fin de cuentas, una literatura desde la que soñar y aprender a ser algo más libres.

\section{BIBLIOGRAFÍA}

Bajtin, M. (1986) Problemas literarios y estéticos, México DF, FCE.

De Caldas Brito, C. (2008) «Migranti: nuove identità a partecipazione sociale attraveso la scrittura?», Lingua e letterature in movimento. Scrittrici emergenti nel panorama letterario italiano contemporaneo, Bologna, Bup, pp. 19-28.

El Kamhawi, E. (2014) Vergogna tra le due sponde. La schiavitù contemporánea nel Mediterraneo, Roma, Ensemble.

Foucault, M. (1984) Des espaces autres, <http://docplayer.es/398354-.html>, [10/01/2016]. 
Grossman, E. (2010) Por qué la traducción importa, Buenos Aires, Katz Editores.

Meneghelli, D. (2012) «Il diritto all'opacità», Scritture migranti, 5, pp. 57-80.

Lakhous, A. (2014) La zingarata della verginella di Via Ormea, Roma, Edizioni e/o.

- (2013) Contesa per un maialino italianissimo a San Salvario, Roma, Edizioni e/o.

- (2010) Divorzio all'islamica a viale Marconi, Roma, Edizioni e/o.

- (2006) Scontro di civiltà per un ascesore a Piazza Vittorio, Roma, Edizioni e/o.

Ovejero Bernal, A. (2012) «Lo que la Literatura puede aportar a la Psicología Social», Ocnos. Revista de estudios sobre lectura, 8, pp. 7-20, <http:// dx.doi.org/10.18239/ocnos_2012.08.01>, [20/01/2016].

Villarroya, E. (2014) «El impacto social de la movilidad humana: una visión no dicotómica del cambio cultural e individual», Mètode, $81,<$ http://metode. cat/es/revista/67-itinerancies>, [03/02/2016].

Zangrando, S. (2010) Storia della Letteratura italiana. Vol. IX, Roma, Salerno Editrice. 